\title{
A FORMAÇÃO DE EDUCADORES NA EDUCAÇÃO NÃO FORMAL PÚBLICA
}

\author{
NADIA FUHRMANN* \\ FERNANDA Dos SANTOS PAULO ${ }^{* *}$
}

RESUMO: O artigo se ocupa da discussão sobre a educação não formal no Brasil contemporâneo. Como subsídios, toma dados de uma pesquisa realizada na Universidade Federal do Rio Grande do Sul sobre o Programa de Apoio Socioeducativo (Sase) e de experiências empíricas da Associação dos Educadores Populares de Porto Alegre (Aeppa), como entidade de formação de educadores populares. Os resultados demonstram que o programa socioeducativo público usa um modelo de ensino-aprendizagem híbrido entre a pedagogia e a assistência social, com lacunas quanto à sistematização e avaliação das atividades, aos conteúdos e à formação dos profissionais que nele atuam.

Palavras-chave: Educação não formal. Formação de educadores. Sase. Aeppa.

\section{EDUCATORS' FORMATION IN PUBLIC NON-FORMAL EDUCATION}

ABSTRACT: The article deals with the discussion on non-formal Education currently in Brazil. The data were obtained from research developed by the Federal University of Rio Grande do Sul concerning the Socio-Educational Support Program (Sase) and from empirical experiences reported in the Popular Educators' Association of Porto Alegre (Aeppa), which is an Institution for the formation of popular educators. The results demonstrate that the public socio-educational program uses a hybrid teaching-learning model between pedagogy and social assistance. However, gaps were found in the systematization and evaluation of the activities, as well as in the contents and formation of professionals involved in the program.

Key words: Non-formal education. Educators' formation. Sase. Aeppa.

\footnotetext{
* Programa de Pós-Graduação em Sociologia da Universidade Federal do Rio Grande do Sul (UFRGS). Porto Alegre (RS) - Brasil.

* Programa de Pós-Graduação em Educação da Universidade Federal do Rio Grande do Sul (UFRGS). Porto Alegre (RS) - Brasil.

Contato com as autoras: <nfuhrmann@bol.com.br>
} 


\title{
LA FORMATION DES ENSEIGNANTS DANS L'ÉDUCATION PUBLIQUE NON-FORMELLE
}

\begin{abstract}
RÉSUMÉ: L'article s'occupe de la discussion sur l'éducation non-formelle au Brésil contemporain. Ayant pour base des données d'une recherche faite à l'Université Fédérale de l'État du Rio Grande do Sul sur le Programme de Soutien Socio-éducatif (Sase), et d'expériences empiriques de l'Association des Enseignants Populaires de Porto Alegre (Aeppa), en tant qu'entité de formation d'enseignants populaires. Les résultats montrent que le programme socio-éducatif public utilise un modèle d'enseignement-apprentissage hybride entre la pédagogie et l'assistance sociale avec des lacunes par rapport à la systématisation et l'évaluation des activités, aux contenus et à la formation des professionnels qui travaillent dans ce domaine.
\end{abstract}

Mots-clés: Éducation non-formelle. Formations d'enseignants. Sase. Aeppa.

\section{Introdução}

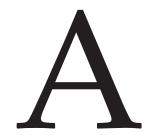

educação não formal é um modelo de ensino-aprendizagem cujo conceito é complexo e ambíguo, composto por uma gama diversificada de práticas pedagógicas assistemáticas ainda pouco investigadas no Brasil. A proposta para o presente artigo é discutir essa modalidade de educação a partir do programa socioeducativo em meio aberto, que se robustece hodiernamente no Brasil. O objetivo precípuo é trazer ao debate algumas diretrizes e concepções atuais sobre o tema, alinhadas aos estudos e experiências empíricas, em especial as do Serviço de Apoio Socioeducativo (Sase) e as da Associação dos Educadores Populares de Porto Alegre (Aeppa), para que, ao serem compartilhadas, possam contribuir com novas pesquisas nessa área, bem como com as atuais e futuras políticas socioeducacionais do país.

Há consenso por parte do governo, das instituições educativas e de estudiosos do tema que o desenvolvimento do Brasil somente se concretizará na medida em que a educação, no mais amplo do seu significado, alcançar seus credores. Essa meta é ambiciosa, especialmente por se tratar de um país com dimensão continental e com infortúnios de ordem atávica que marcam as crianças e os jovens das classes populares, como os vínculos familiares fragilizados, a pobreza material, a "rualização", as violências difusas, o uso de drogas, as humilhações e os maus-tratos, o trabalho infantil, a formação pré-escolar inexistente ou deficitária, a evasão escolar, o alto índice de analfabetismo funcional, as reincidentes repetências, para citar apenas alguns. Tanto um saudável ambiente protetivo primário quanto uma formação pré-escolar de qualidade são requisitos básicos para a concretização da excelência científica e de inovação que o sistema educacional brasileiro almeja para o futuro próximo. O investimento em pesquisas com potencial aplicável para o desenvolvimento tecnológico e social alcançará seu objetivo quanto maior for o investimento 
na primeira infância. ${ }^{1}$ Para suprir esse déficit será necessário enfrentar alguns desafios, e dentre eles se destacam o pleno acesso aos serviços socioeducativos em meio aberto e a formação de profissionais de nível superior para a demanda da educação social complementar.

Para fins de sistematização, o texto é composto por três partes: a primeira versa sobre a concepção de educação não formal e sobre o controvertido conceito dessa categoria, utilizado, muitas vezes, sem definição clara para designar toda e qualquer ação educativa fora do âmbito curricular formal. Na segunda parte está descrita a fundação e a trajetória da Associação de Educadores Populares de Porto Alegre (Aeppa) como instância de apoio aos profissionais de educação não formal, que almejam qualificação e formação continuada de qualidade para o exercício de suas atividades pedagógicas. A terceira e última parte explora os fundamentos do serviço socioeducativo como espaço institucionalizado da educação não formal, organizado no bojo das políticas de assistência social. Para tanto, apresenta dados de uma pesquisa sobre o Serviço de Apoio Socioeducativo (Sase) de Porto Alegre, realizada no Programa de Pós-Graduação de Sociologia da Universidade Federal do Rio Grande do Sul (UFRGS), no interstício 2010-2011.

\section{A educação não formal no Brasil contemporâneo}

Educar é uma ação voltada ao saber-conhecer-fazer e se constitui num amplo processo de aprendizagem natural imanente ao homem, desde o seu nascimento até a sua descorporificação. Portanto, viver já é por si só uma experiência pedagógica humana necessária à sobrevivência, reprodução e evolução da espécie. As primeiras experiências educativas se realizam através dos instintos e da cultura familiar e comunitária, sucessivamente reproduzidas por meio genético-transgeracional. A educação básica forja nos pequenos uma visão de mundo irredutível. Neste ciclo de vida, são as primeiras experiências com o cuidador, com a família e com a rede social que vão orientar a conduta e a formação da criança nos níveis primário, secundário e terciário. Os estudos de René Spitz já demonstraram, na década de 1930, que as experiências formativas no ambiente familiar e comunitário inicial influenciam tanto afetivamente quanto cognitivamente o ser humano por toda a sua existência (SPITZ, 2004).

Por outro lado, Flickinger (2011), se referindo ao estágio da pedagogia intermediária, escreve que o objetivo último da formação tradicional curricular moderna, herdada do Iluminismo, é levar o sujeito à maioridade e consequente autonomia e perfeição. Tal meta é ficcional e narcísica e, portanto, não colabora para a construção de uma sociedade justa e solidária. $\mathrm{O}$ autor, ao investigar a herança do conceito de Bildung, ${ }^{2}$ adverte que: 
[...] o próprio idealismo alemão já havia percebido a importância desta qualidade da autonomia. Foi, sobretudo, a filosofia de Hegel que trouxe essa base social à luz. Segundo ele, querer levar o indivíduo à maturidade equivale à tarefa de ajudá-lo a se autoentender como ser social. A autonomia, segundo Hegel, resulta de uma aprendizagem social que passa pela figura do reconhecimento. Aprendizagem sem a qual os educandos permaneceriam no estágio de seres egoístas, presos à ficção da sua onipotência e incapazes de aceitar sua própria inserção na rede social. (FLICKINGER, 2011, p. 160)

A formação integral, composta pela educação formal, não formal e social, se tece por meio de uma complexa articulação entre saberes e práticas educativas com objetivo de desenvolver nos indivíduos aptidões e competências emocionais, sociais e políticas, em diversificados espaços de aprendizagem. Para isso, são necessárias políticas educacionais integralizadas que se ocupem de forma homogênea da indissociabilidade dos três níveis de desenvolvimento e formação humana, tanto para os educandos quanto para os educadores.

Complementar à educação curricular, entende-se por educação não escolar as atividades pedagógicas exercidas numa perspectiva da educação social, da educação não formal e da educação informal. Assim, nomina-se de educação social o conjunto organizado de conhecimentos científicos oriundos da Pedagogia Social, que subsidiam processos didáticos, pedagógicos e metodológicos específicos para o desenvolvimento humano e social. Não tem por objetivo precípuo o ensino curricular/ disciplinar, mas o despertar das potencialidades do indivíduo de acordo com o seu ciclo de vida, fortalecendo-o para a vida em sociedade a partir da consciência de cidadania. A metodologia da educação social remonta aos estudos dos alemães Mager e Diesterweg, por volta do ano de 1900. Esse modelo de ensino-aprendizagem pressupõe a articulação entre os saberes teóricos e os saberes advindos da prática do mundo da vida cotidiana, com o fim de arrefecer as situações de vulnerabilidade dos indivíduos com necessidade de proteção assistencial. Para a concretização da educação social de qualidade são imprescindíveis políticas sociais específicas e uma legislação que regulamente o ensino e o trabalho docente (DÍAZ, 2006) do professor socioeducativo em meio aberto.

Na esteira do que afirma Ghanem Jr., Trilla, Arantes (2008), a educação não escolar abrange práticas educativas informais e não formais, cuja especificidade é a incipiente sistematização. O tipo de aprendizado informal sofre influência de situações cotidianas, geralmente sem nenhum controle externo, como, por exemplo, a observação das atitudes de outras pessoas na rua, assistir à televisão, ouvir música, ler, navegar na internet, jogar, brincar, entre outros. Não há roteiro, método ou mesmo objetivos definidos nessa prática educativa. Outro tipo de aprendizado não escolar é o não formal, que pressupõe certo controle e uma sistematização sobre um determinado conteúdo disciplinar extraclasse. No Brasil, tal modalidade educativa admite a presença de um educador sem formação superior, que orienta atividades 
de ordem lúdica e esportiva, psicossocial e de cidadania. São exemplos de educação não formal os programas socioeducativos e a educação popular.

A educação social e a não formal são modalidades de ensino-aprendizagem que oferecem importantes subsídios educativos para o aprimoramento das diferentes inteligências que englobam os aspectos lógicos e emocionais do indivíduo (GARDNER, 2007). Portanto, distante de serem alternativas, representam a chave para a ascensão social e econômica das classes populares alijadas por um sistema educacional elitista ainda praticado no Brasil.

Há cerca de duas décadas, vislumbra-se uma força-tarefa integralizada entre a assistência social e a pedagogia, com vistas à organização, sistematização e qualificação da educação não formal no país. Deste esforço surgiu o Serviço de Apoio Socioeducativo em meio aberto (Sase) e, mais recentemente, o Serviço de Convivência e Fortalecimento de Vínculos alinhado às políticas do Ministério do Desenvolvimento Social. São protagonistas desse processo as classes populares que lutam por espaços educativos de qualidade para seus filhos, as instituições beneficentes ligadas a ações assistenciais e os movimentos de classe como, por exemplo, a Associação de Educadores Populares de Porto Alegre (Aeppa).

\section{A origem e a trajetória da Associação de Educadores Populares de Porto Alegre (Aeppa)}

A Aeppa foi fundada na década de 1990, fruto do trabalho realizado por lideranças comunitárias que atuavam junto a entidades beneficentes, que mantinham creches vinculadas à assistência social por meio de programas não formais de educação infantil.

O seu surgimento tem a ver com a luta pela dignidade e direitos da infância no Brasil, capitaneada pela Legião Brasileira de Assistência (1942-1995) e alicerçada na Constituição Federal (1988), no Estatuto da Criança e do Adolescente (1990), na Lei de Diretrizes e Bases da Educação Nacional (1996), na Lei Orgânica da Assistência Social (1993), concomitante às demandas advindas das mães que precisavam trabalhar e necessitavam de creches ou de espaços educativos para deixarem seus filhos, no turno inverso da escola fundamental.

Portanto, foi no contexto político da década de 1990 que nasceu a Aeppa, tendo por objetivo viabilizar a formação de educadores populares em sintonia com as necessidades e os saberes comunitários e demais projetos e programas executados pelas instituições que prestavam esse atendimento. Entre os anos de 1996 e 1997, um número significativo de educadores populares das diferentes regiões de Porto Alegre se mobilizou para reivindicar formação profissional à luz da educação popular 
(PAULO, 2010; FLORES, 2007). O movimento se fortaleceu a partir de uma nota de jornal que aludia sobre a exigência de formação no nível médio para atuar na educação infantil (LDBEN, 1996, art. 62). Segundo Paulo (op. cit., p. 23),

Os primeiros responsáveis pelo cuidado e guarda das crianças foram as mulheres e algumas lideranças comunitárias que tinham uma forte preocupação e vínculo com as crianças das quais cuidavam. Essas educadoras, percebendo a tamanha demanda por espaços educativos não escolares, organizaram-se, articuladas pelo conselho tutelar da região Glória, com base nos artigos 86 e 87 do Estatuto da Criança e Adolescente (Lei n. 8. 069/90), indo para frente da Prefeitura de Porto Alegre juntamente com os familiares das crianças que frequentavam as creches, com objetivo de reivindicar direitos estabelecidos na lei. O Conselho Municipal dos Direitos da Criança e do Adolescente (CMDCA) e demais Conselhos Tutelares da cidade aderiram à manifestação, a fim de garantir o atendimento integral das crianças nas instituições que ofereciam esses cuidados. Esta reivindicação não era apenas de alguns locais, mas de todas as vilas situadas nos bairros mais empobrecidos da cidade de Porto Alegre.

Dessa mobilização foi-se formado um grupo de estudo denominado "Comissão de Educação", cujo objetivo foi o de estudar, discutir e planejar um curso de formação que pudesse contemplar a realidade das creches comunitárias. Essa comissão passou a se encontrar periodicamente, a fim de traçar estratégias para reivindicar ao Estado a formação exigida em lei. A comissão se tornou uma Associação no ano de 2000, quando já havia trilhado uma longa luta para o chamado "extraclasse" (1995), depois denominado de Serviço de Apoio Socioeducativo - Sase (1997) e, atualmente, alcunhado de Serviço de Convivência e Fortalecimento de Vínculos (2010), cuja meta é atender crianças e adolescentes em idade escolar no turno inverso ao da escola curricular, com atividades de educação não formal.

Completados 13 anos de existência como Associação, hoje a Aeppa tem por finalidade buscar espaços de formação para educadores populares e sociais nos níveis fundamental, médio, médio técnico e superior, garantindo a qualificação profissional de muitos trabalhadores que atuam na educação infantil, pré-escolar e também em serviços de apoio socioeducativos; trabalho educativo; oficinas; educação de jovens e adultos; educação nos abrigos; educação de rua e demais campos não escolares, mas institucionalizados como programas e serviços públicos (AEPPA, 2012).

A Constituição de 1988, o Estatuto da Criança e do Adolescente (Eca) de 1990 e a Lei de Diretrizes e Bases da Educação Nacional (LDBEN) de 1996 ofereceram avanços em relação aos direitos da infância e da juventude, mas ao início não priorizaram o Estado como executor direto das políticas de educação infanto-juvenis. No caso do Rio Grande do Sul, foi a sociedade civil organizada porto-alegrense a responsável por grande parte do atendimento e ampliação da oferta de educação não formal para crianças e adolescentes carentes, mediante parcerias com a Secretaria Municipal de Educação (SMED) e a Fundação de Assistência Social e Cidadania 
(Fasc), pela via dos convênios. O exemplo é o Sase, oferecido pela Fasc, com 630 vagas na rede própria e 8.814 na rede conveniada, totalizando 9.444 vagas. $^{3}$

Grande parte dos educadores populares é oriunda das comunidades locais e, de alguma forma, possuem uma relação com o movimento comunitário. A maioria deles tem o ensino fundamental e conhecimentos sobre o trabalho da instituição onde atuam por meio das lideranças locais. Aqueles que trabalham com a educação infantil são chamados de educadores sociais e contratados como "educadores assistentes", "recreacionistas", "atendentes" ou, ainda, "monitores", independentemente de possuir a habilitação profissional em licenciatura em nível superior, de acordo com a LDBEN (1996, art. 62).

É importante sublinhar que o convênio não cobre o salário do cargo de professor, o que obstaculiza a contratação de educadores sociais com qualificação profissional ou mesmo a permanência deles quando concluem o curso. As parcas instituições que mantêm educadores sociais com ensino superior os remuneram com recursos próprios.

A regra até pouco tempo foi a formação mínima no ensino fundamental, mas muitos educadores buscaram ou já possuem o curso de qualificação denominado de "educador assistente", como exigência mínima do Conselho Municipal de Educação (CME/POA) e da SMED. Segundo preconiza a Comissão Municipal de Educação de Porto Alegre, deve haver um trabalho em conjunto entre professor e educador assistente, mas na prática não é o que comumente ocorre. A partir de relatos das educadoras e dos educadores participantes da Aeppa, o "professor" é o "educador assistente", e este exerce as duas funções. Registra-se ainda a situação em que alguns dos educadores possuem o "magistério/normal", mas são contratados como "educadores assistentes".

Atualmente, na cidade de Porto Alegre, a maioria dos "educadores assistentes" ainda possui pouca escolaridade, as condições estruturais das entidades são limitadas e os recursos financeiros para esse estágio da educação são insuficientes, o que faz permanecer a mensalidade facultativa das famílias para a manutenção das creches comunitárias, por exemplo. Segundo dados do Censo Escolar da Educação Básica de 2011, divulgados pelo Instituto Nacional de Estudos e Pesquisas Educacionais (Inep), houve um crescimento no atendimento à educação infantil, fundamentalmente através das creches (CORREIO DO POVO, 2012). São dados como esses que hoje as educadoras e os educadores populares levam às reuniões e aos encontros da Aeppa. Nesse espaço, são discutidas as relações deles com a comunidade, com o trabalho e com a formação. Para tanto, estudam a legislação pertinente à educação e à assistência social no Brasil, a obra de Paulo Freire e autores afins, assim como documentos que fazem referências às suas áreas de atuação. Nos encontros, buscam 
construir ferramentas próprias de luta por formação, que, para além de um direito do trabalhador, seja a garantia de atendimento qualificado à infância e juventude das comunidades populares.

Nos últimos anos, a Aeppa organizou alguns cursos de formação profissional para os educadores populares e lideranças comunitárias que qualificaram suas ações junto aos usuários e à comunidade, como, por exemplo, parcerias com o curso normal nas escolas municipais Emilio Meyer e Liberato Salzano Vieira da Cunha (AZEVEDO, 2007; FLORES, 2007; PAULO, 2010), e com os de graduação da Universidade do Estado do Rio Grande do Sul (UERGS), do Centro Universitário Metodista Sul (IPA) e da Pontifícia Universidade Católica do Rio Grande do Sul (PUCRS) (AZEVEDO, 2007; FLORES, 2007; PAULO, 2010; LORD, 2011) e com os cursos de pós-graduação em Educação Popular e Gestão de Movimentos Sociais, em conjunto com o Instituto Superior de Educação, de Ivoti, e o Instituto de Desenvolvimento Social Brava Gente (SILVA; PAULO; GRAZZIOLA, 2010).

Paradoxalmente, ainda não existe por parte da prefeitura de Porto Alegre uma política de valorização e reconhecimento profissional relativa à educação social, gerando grandes dificuldades para a Aeppa em torno da formação dos educadores sociais, pois as iniciativas até então desenvolvidas trouxeram outras situações problemáticas referentes ao processo de qualificação dos educadores, sobretudo nas questões que dizem respeito às relações de trabalho. Entre elas, temos a retomada do diálogo com a Universidade do Estado do Rio Grande do Sul (UERGS) e com a Universidade Federal do Rio Grande do Sul (UFRGS) para a oferta de um curso de Pedagogia Social. Isso porque a Aeppa se mantém na luta para garantir uma formação superior para os educadores populares e busca como prioridade cursos de Pedagogia com ênfase em educação social. Cursos de Pedagogia Social são fundamentais para o desenvolvimento de métodos, ferramentas, competências e habilidades profissionais específicas para o trabalho em creches, no Sase, no Movimento de Alfabetização de Jovens e Adultos (Mova) e em outros espaços já consolidados de educação não formal.

Quanto às limitações, a Aeppa não possui até o momento uma sede própria. As suas reuniões acontecem em diferentes espaços de Porto Alegre, como na sala 10 do mercado público ou na Instituição Pão dos Pobres. Decorrente dessa situação, a Aeppa não tem a visibilidade e o alcance que necessita para a organização eficaz dos educadores sociais. Outro obstáculo é o fato de muitos dirigentes, equivocadamente, terem receio de perder seus educadores caso estes se associem à Aeppa e busquem qualificação. Os trabalhadores e as trabalhadoras, por não terem uma formação específica, não se reconhecem como educadores populares; muitos não têm acesso à internet para acompanhar o blog que divulga as ações da Aeppa. 
Essas são pistas que podem levantar elementos para pensar estratégias de adesão por parte de educadores populares, a fim de lutarem pelo direito à formação profissional que leve em conta todas as formas de educação formal, não formal e informal (GOHN, 2010).

A Aeppa luta pela qualidade nos programas e serviços de educação não formal, destinados ao segmento infanto-juvenil das classes desprivilegiadas econômica e socialmente. Para tanto, almeja a implantação de cursos de graduação onde a "experiência social" (FREIRE, 1978) seja valorizada nas propostas de formação para os educadores sociais, concomitante aos saberes acadêmicos, sem a predominância de um sobre o outro.

Um importante passo para a regulamentação do trabalho em educação social foi alcançado pelo Projeto de Lei n. 5.346, de 2009, que cria a profissão de educador social. Embora, num primeiro momento, a profissionalização do educador social, a partir desse projeto de lei, seja considerada como avanço, um dos seus limites está na exigência do ensino médio como requisito para o desempenho da função. Em oposição, a Aeppa julga que o ensino médio como primeiro nível de formação para o exercício da profissão de educador social já aponta uma demanda de cursos formativos no nível superior, de acordo com os próprios princípios da educação social. A Aeppa almeja a formação de nível universitário para todos os educadores reconhecidos agora como "educadores sociais" (profissão), para que possam construir seu percurso formativo e de carreira concomitante à sua trajetória junto às comunidades. Desse ponto de vista, o Projeto de Lei de n. 5.346 cumprirá seu legado para a educação não formal no Brasil se conceber a educação como um processo integral, que não dissocia os saberes do "mundo da vida" (HABERMAS, 1982) dos saberes do mundo historicamente construído e legitimado pela academia.

\section{O Serviço de Apoio Socioeducativo em Porto Alegre}

Outra importante iniciativa para a qualificação do ensino não formal público é o Serviço de Apoio Socioeducativo (Sase). Para uma descrição do Sase de Porto Alegre, consideram-se os resultados de uma pesquisa realizada na UFRGS, no Núcleo de Pesquisa "Violência e Cidadania", do Programa de Pós-Graduação em Sociologia da UFRGS, no interstício 2010/2011, financiada pelo CNPq (FUHRMANN, 2011). O estudo de caráter qualitativo verificou o potencial preventivo do Sase quanto à redução das violências e situação de rualização do segmento infanto-juvenil na capital. Para lograr êxito, foi examinado o processo de implantação, a metodologia pedagógica e o conteúdo programático do Programa em duas instituições caritativas da rede conveniada com a Fasc. Os dados primários foram obtidos de um total de 32 entrevistas e de dois grupos focais com crianças e jovens do Programa, bem como com 
educadores sociais, coordenadores e profissionais que atuam diretamente no Sase. A hipótese se baseou na premissa de que, diante da possibilidade de falha efetivada na consolidação das estruturas de formação da identidade prática de crianças e adolescentes frente a situações de vulnerabilidade social, o Sase, cujo método é baseado em procedimentos socioeducativos, que prioriza conteúdos pertinentes às três dimensões nomeadas pela Teoria do Reconhecimento de Axel Honneth (2009), a saber: o amor, o direito e a solidariedade, tem papel fundamental no resgate e na recuperação e reinserção social das crianças e dos adolescentes das classes populares. Tendo em vista a limitação espacial, compartilha-se a seguir parte dos resultados do estudo. Uma versão mais detalhada dessa pesquisa é encontrada em Fuhrmann (2013).

O Sase de Porto Alegre pode ser considerado um exemplo paradigmático de construção e implantação de uma rede de apoio educacional não formal e complementar à escola curricular. As origens do que hoje se constitui o Serviço em Porto Alegre remonta ao início dos anos de 1990. Em entrevista, o diretor de uma entidade beneficente conveniada que oferece o Serviço narra a fase embrionária do Programa:

\begin{abstract}
Eu já trabalho nessa área desde 1988 e tenho uma relação com esta Instituição desde 1992, faz na verdade 20 anos de casamento, mas em 1993 eu comecei a fazer esse trabalho que a gente chamava de apoio sociofamiliar, que era justamente coletando informações das crianças pra que essas informações pudessem chegar ao educador pra que o educador pudesse melhor trabalhar no rendimento. Isso, na época, qualificaria a relação do educador com o pedagógico e a criança. Mas, a partir de 1992 para 1993, aí a prefeitura começa a fazer os primeiros convênios do Sase. O primeiro nome foi parece que Projeto Borboleta, agora eu não lembro bem se era outro nome. Eu trabalhei na prefeitura na época e o que acontece é que o Sase estava dentro da Secretaria de Educação, mas por uma reestruturação da política, o Sase passou a ser da Fesc, que era uma fundação dentro da prefeitura que cuidava da questão do esporte e da cultura, esporte e lazer, mas ela também não sabia muito bem o que fazer com o extraclasse, como era chamado este programa, e daí começou a cumprir aquilo junto com as entidades. O Sase foi uma construção conjunta da prefeitura com as entidades beneficentes de Porto Alegre. De 1991 até 1993 nós trabalhamos com o nome extraclasse, em 1993 já adotamos a nomenclatura Sase. Mas, oficialmente, na prefeitura começou em 1995, o primeiro documento é datado de abril de 95. Claro que ele foi sofrendo muitas alterações, o primeiro documento oficial que tu vais encontrar, se não me engano, é de 2003. Efetivamente, o Sase foi construído com a colaboração das instituições assistenciais da cidade. (FUHRMANN, 2011)
\end{abstract}

Considerando a digressão histórica narrada pelo partícipe do processo, é possível inferir que o Serviço de Apoio Socioeducativo em meio aberto, em Porto Alegre, resultou de uma construção coletiva entre a esfera pública municipal e as organizações privadas de caráter filantrópico que se ocupavam em prestar assistência às crianças e aos jovens das classes populares, em período extraclasse curricular, no início da década de 1990. Tecendo os fios, observa-se que o Sase, na capital rio-grandense, teve sua 
origem no âmbito das políticas sociais na área da educação, funcionando por curto período como extraclasse. Na sequência, por pressão das entidades de caridade, expostas ao cotidiano de vulnerabilidade social das crianças, dos jovens e suas famílias, o Sase foi integrado no bojo das políticas de assistência social e, a partir de então, vem sendo desenvolvido e aprimorado até o momento. ${ }^{4} \mathrm{O}$ Serviço resistiu às mudanças de governo e se tornou uma política social municipal permanente. Desde o final do ano de 2009 está vinculado no nível federal ao Ministério do Desenvolvimento Social/ Assistência Social como um serviço de proteção social básica, financiado pelo Fundo de Assistência Social nacional e municipal. Acredita-se que as sucessivas tentativas de sistematizar, organizar e normatizar os serviços socioeducativos, no nível municipal, em todo o Brasil, foram em parte reparadas pela Resolução CNAS n. 109, de 11 de novembro de 2009, que aprovou a Tipificação Nacional dos Serviços Socioassistenciais, em conformidade com a Lei Orgânica da Assistência Social (Loas) e com o Estatuto da Criança e do Adolescente (ECA), designando diretrizes mínimas para a implantação e funcionamento dos Sase. ${ }^{5}$ A partir dessa resolução, os serviços de apoio socioeducativos em meio aberto passaram a ser normatizados pela Assistência Social com a denominação de Serviço de Convivência e Fortalecimento de Vínculos. No entanto, na prática, no dia a dia do Serviço institucionalizado, pouco mudou. A alteração tem mais a ver com a premência de uma fonte de recursos permanente para a manutenção do serviço do que propriamente com uma proposta pedagógica.

Em outras palavras, atualmente os serviços de apoio socioeducativos em meio aberto estão organizados dentro do Sistema Único de Assistência Social (Suas), referenciados pelos Centros de Referência de Assistência Social (Cras - municipal) dentro da gradação de baixa complexidade, nominado como Serviço de Convivência e Fortalecimento de Vínculos. O Serviço tem como público-alvo o segmento infantojuvenil, em situação de vulnerabilidade e risco social, na faixa etária de 6 a 17 anos, divididos em dois serviços: o Serviço de Apoio Socioeducativo (Sase) e o Trabalho Educativo (TE). Ambos os serviços são oferecidos exclusivamente para as classes populares, admitindo crianças e adolescentes em horário inverso ao da escola regular, com carga horária de quatro horas. Objetivam o fortalecimento dos vínculos familiares e comunitários pautados pela perspectiva da inclusão social, emancipação, autonomia através do desenvolvimento de competências para a compreensão crítica da realidade social contemporânea. Para além, contribuem para a inserção, reinserção e permanência de jovens e crianças no meio escolar formal. ${ }^{6}$ Na Tipificação Nacional de Serviços Socioassistenciais estão descritos os critérios de ingresso da demanda nos serviços; o objetivo e as provisões institucionais necessárias para o convênio público, como, por exemplo, o ambiente físico adequado, trabalho social essencial e recursos materiais e humanos. Porém, de acordo com pesquisas e trabalhos realizados recentemente sobre o Sase em Porto Alegre, ainda existem dificuldades de 
ordem pedagógica e de formação de recursos humanos que podem colocar em risco a excelência do serviço.?

Com efeito, a Resolução de n. 109, do Conselho Nacional de Assistência Social, normatiza os serviços socioeducativos em todo o país sob os aspectos dos seus objetivos, usuários e provisões mínimas para a oferta e funcionamento, tanto na rede própria municipal quanto em instituições conveniadas de caráter assistencial. A Norma Operacional Básica de Recursos Humanos (NOB-RH) do Sistema Único de Assistência Social (Suas), Resolução n. 17, de 20 de junho de 2011, por sua vez, estabelece os profissionais de nível superior, assistente social e psicólogo como essenciais nos serviços de proteção básica, e profissionais graduados nas áreas de antropologia, economia doméstica, pedagogia, sociologia, terapia ocupacional e musicoterapia para o atendimento às especificidades dos serviços nos Cras. No entanto, esta mesma Norma não explicita as competências e habilidades profissionais desejadas para os serviços socioeducativos em meio aberto, não propõe orientação quanto às atividades lúdicas e esportivas e ao conteúdo programático mínimo a ser ministrado, não há clareza quanto ao perfil de formação e sequer uma estratégia de capacitação profissional especializada e continuada. A ausência de orientação legal para o trabalho socioeducativo despersonaliza o Serviço e cria obstáculos de qualidade de nivelamento entre os estabelecimentos que o executam. Assim, a qualificação profissional dos educadores sociais, das coordenações, da equipe multiprofissional de suporte, e o conteúdo programático das atividades não formais variam entre as instituições. Vale lembrar que tais condições interferem e discriminam o Serviço entre as entidades ofertantes, e causam prejuízos aos educandos, dependendo dos recursos físicos e materiais da instituição onde esses estão inseridos. O encaminhamento dos usuários ao Sase obedece ao critério de territorialização, ou seja, as vagas são ofertadas preferencialmente nas instituições da abrangência de residência das crianças e adolescentes e, portanto, não há escolha por parte das famílias.

De fato, o Sase como método pedagógico não formal se constitui em um serviço assistencial e educacional protetivo e preventivo com importante capacidade de reinserção social do segmento infanto-juvenil das classes populares. Todavia, apresenta lacunas na organização e sistematização das atividades lúdicas e do conteúdo programático ministrado, assim como formação insuficiente e inadequada dos recursos humanos que atuam no Serviço.

\section{Considerações finais}

Para dar prosseguimento ao debate, propõe-se pensar sobre três questões ainda pouco desenvolvidas no âmbito da educação não formal institucionalizada no Brasil. O primeiro ponto diz respeito à persistência de uma visão que coloca em oposição 
educação não formal e educação curricular ou formal. Na prática, as duas modalidades de ensino-aprendizagem fazem parte de um mesmo processo, como sístole e diástole, imanente do ciclo de educação de crianças e adolescentes. Possuem funções distintas, mas são complementares e indispensáveis ao funcionamento da complexa teia que forma o sistema educacional no país. É fato que a cartografia da educação stricto sensu transpõe territórios escolares formais. A primeira questão que merece reflexão é por que a inclusão de diretrizes e orientações claras para a prática pedagógica não formal se encontra ainda incipiente na legislação educacional brasileira?

Um segundo item importante a ser considerado remete à constituição híbrida do Sase, considerado o mais importante programa organizado de educação não formal no Brasil. Embora lotado no bojo das políticas de assistência social, pressupõe conteúdo e formação pedagógica. A indefinição das competências e das habilidades de formação daqueles que exercem as funções de planejar, coordenar e de educar nos serviços socioeducativos em meio aberto se configura em obstáculo à qualificação das atividades e dos conteúdos programáticos ministrados no Sase. Em médio prazo, não solucionado o problema, não estaria em risco a eficácia do programa socioeducativo em meio aberto no Brasil?

Uma última questão a ser sublinhada sobre a educação curricular, não formal e social é que essas são as mais valiosas ferramentas contra a desigualdade e a exclusão social e se configuram em conjunto uma política social do reconhecimento. ${ }^{8} \mathrm{Em}$ consequência, se mostra relevante no âmbito dos municípios brasileiros a criação de associações de educadores sociais que possam dar suporte à categoria quando à sua formação e direitos, concomitante com a implantação de cursos superiores de Pedagogia Social. Por outro lado, também se mostra necessária a inclusão de disciplinas pedagógicas nos currículos dos cursos de Serviço Social. Tanto a pedagogia quanto o serviço social se mostram como áreas do saber imprescindíveis para qualificação dos serviços socioeducativos no Brasil. Todavia, terão os egressos desses cursos formação adequada para exercerem qualificadamente atividades nesse programa?

Infere-se que o investimento do governo brasileiro em políticas de redistribuição e geração de renda, bem como as ações afirmativas para o ingresso no ensino terciário são imprescindíveis para desarraigar a pobreza econômica de parte das famílias brasileiras. Alerta-se, todavia, que tais políticas sociais são insuficientes para incluir seus filhos na atual sociedade do conhecimento e desconstruir o apartheid de classes, remanescente de um Brasil arcaico e colonial superado. Ao que tudo indica, no conjunto dos esforços para erradicar a desigualdade social no país e arrefecer as situações de exclusão, vulnerabilidade e violência em que as classes populares estão expostas diuturnamente, a educação não formal institucionalizada, em especial, cumpre missão fundamental e, portanto, carece de mais atenção e investimentos por parte do governo brasileiro. 


\section{Notas}

1. Palestrante na Fundação Getúlio Vargas (6 de maio de 2012), James Heckman, economista e Prêmio Nobel em 2000, explicitou para professores e alunos de pós-graduação e na presença do Ministro da Educação, Aloisio Mercadante, que a base da educação inicia antes da pré-escola. Heckman citou estudos que demonstram que investimentos na educação de crianças entre 0 e 3 anos têm uma taxa de retorno muito maior do que os investimentos na educação curricular e superior. Ainda salientou que a falta de atenção à primeira infância, em especial nas famílias carentes, perpetua as desigualdades sociais e econômicas. Infelizmente, Mercadante admitiu que no Brasil a educação pré-escolar ainda se encontra distante do ideal. Disponível em: <http://gazetaonline.globo.com/_conteudo/2012/05/ noticias/minuto_a_minuto/nacional/1223264-brasil-deve-investir-na-pre-escola-diz-nobel.html >. Acesso em: 7 maio 2012.

2. Traduzido da língua alemã como "Formação".

3. Fundação de Assistência Social e Cidadania. Prefeitura Municipal de Porto Alegre. Informações disponíveis em: <http://www.portoalegre.rs.gov.br/fasc>

4. Em sintonia com a origem e a trajetória da Associação dos Educadores Populares de Porto Alegre.

5. Ver: Tipificação nacional de serviços socioassistenciais. Disponível em: <www.mds.gov.br $>$, na aba da Assistência Social. Acesso em: 20 mar. 2012.

6. Idem.

7. Vide Fuhrmann (2011), Paulo (2010), Luz (2010) e Oliveira (2007).

8. No sentido que Axel Honneth dá ao conceito de reconhecimento: sujeitos inseridos na estrutura social, vivenciando experiências intersubjetivas positivas nas esferas do amor, do direito e da solidariedade.

\section{Referências}

ASSOCIAÇÃO DE EDUCADORES POPULARES DE PORTO ALEGRE (AEPPA). Disponível em: <www.aeppa-poa.blogspot.com>. Acesso em: 1 jun. 2012.

AZEVEDO, J.C. Reconversão cultural da escola: mercoescola e escola cidadã. Porto Alegre: Sulina, 2007.

BRASIL. Constituição (1988). Constituição da República Federativa do Brasil. São Paulo: Impressão Oficial do Estado, 1988.Estabelece

BRASIL. Lei n. 8.069, de 13 de julho de 1990. Dispõe sobre o Estatuto da Criança e do Adolescente e dá outras providencias. Diário Oficial da União, Brasília, DF, 16 jul. 1990.

BRASIL. Lei n. 8.742, de 7 de dezembro de 1993. Dispõe sobre a organização da Assistência Social e dá outras providencias. Diário Oficial da União, Brasília, DF, 8 dez. 1993.

BRASIL. Lei n. 9.394, de 20 de dezembro de 1996. Estabelece as diretrizes e bases da educação nacional. Diário Oficial da União, Brasília, DF, 23 dez. 1996.

BRASIL. Ministério do Desenvolvimento Social e Combate à Fome. Conselho Nacional de Assistência Social. Resolução n. 109, de 11 de novembro de 2009. Aprova a 
tipificação nacional de Assistência Social. Diário Oficial da União, Brasília, DF, 25 nov. 2009. Seção I, n. 255.

BRASIL. Ministério do Desenvolvimento Social e Combate à Fome. Conselho Nacional de Assistência Social. Resolução n. 17, de 20 de junho de 2011. Ratificar a equipe de referência definida pela Norma Operacional Básica de Recursos Humanos do Sistema Único de Assistência Social (NOB-RH) e reconhecer as categorias profissionais de nível superior para atender as especificidades dos serviços socioassistencias e das funções essenciais de gestão do Sistema Único de Assistência Social. Diário Oficial da União, Brasília, DF, 21 jun. 2011. Seção I, n. 118, p. 79

DÍAZ, A.S. Uma aproximação à Pedagogia: Educação Social. Revista Lusófona de Educação, Lisboa, n. 7, p. 91-104, 2006.

DIMINUI matrícula na Educação Básica. Censo Escolar, 2011. Correio do Povo, Porto Alegre, v. 117, n. 213, abr. 2012. Disponível em: <http://www.correiodopovo.com. br>. Acesso em: 2 maio 2012.

FLICKINGER, H.-G. Herança e futuro do conceito de formação (Bildung). Educação E Sociedade, Campinas, v. 32, n. 114, p. 151-167, 2011.

FLORES, M.L.R. Movimento e complexidade na garantia do direito à educação infantil: um estudo sobre políticas públicas em Porto Alegre (1989-2004). 2007. 289f. Tese (Doutorado em Educação) - Faculdade de Educação, Universidade Federal do Rio Grande do Sul, Porto Alegre.

FREIRE, P. Cartas à Guiné-Bissau: registros de uma experiência em processo. 2. ed. Rio de Janeiro: Paz \& Terra, 1978.

FUHRMANN, N. A busca pelo reconhecimento intersubjetivo e social recusado do segmento infanto-juvenil em situação de rua: um estudo sobre o Serviço de Apoio Socioeducativo (Sase), da Prefeitura de Porto Alegre. Porto Alegre: PPG Sociologia/UFRGS, 2011. 46f. (Relatório de Pesquisa Posdoc/CNPq).

FUHRMANN, N. O primado do reconhecimento sobre a redistribuição: a origem dos conflitos sociais a partir da teoria honnethiana. Sociologias, Porto Alegre, v. 15, n. 33, p. 170-203, maio-ago. 2013.

GARDNER, H. Cinco mentes para o futuro. Porto Alegre: Artmed, 2007.

GHANEM JUNIOR, E.; TRILLA, J.; ARANTES, V.A. (Org.). Educação formal e não formal. São Paulo: Summus, 2008.

GOHN, M.G. Educação não formal e o educador social: atuação no desenvolvimento de projetos sociais. São Paulo: Cortez, 2010. 
HABERMAS, J. Teoría de la acción comunicativa: complementos y estudios previos. Madrid: Cátedra, 1982.

HONNETH, A. Luta por reconhecimento: a gramática moral dos conflitos sociais. 2. ed. São Paulo: Editora 34, 2009.

LORD, L. Educação, política e periferia: estudo sobre o movimento de educadores populares em Porto Alegre. 2011. Tese (Doutorado em Filosofia) - Instituto de Filosofia e Ciências Humanas, Universidade Estadual de Campinas, Campinas.

LUZ, J.H. Educação escolar e apoio socioeducativo: um diálogo a ser construído. 2010. 58f. Trabalho de Conclusão de Curso (Graduação) - Faculdade de Educação, Universidade Federal do Rio Grande do Sul, Porto Alegre.

OLIVEIRA, L.H. As políticas públicas e as práticas socioeducativas voltadas à criança e ao jovem. 2007. 111f. Dissertação (Mestrado em Psicologia) - Programa de Pós-Graduação em Psicologia Social, Universidade Federal do Rio Grande do Sul, Porto Alegre.

PAULO, F.S. Formação dos/as educadores/as populares de Porto Alegre formados/as em Pedagogia: identidade, trajetória e desafios. 2010. 79f. Trabalho de Conclusão de Curso (Especialização em Educação Popular) - Instituto Superior de Educação Ivoti \& Instituto de Desenvolvimento Brava Gente, Porto Alegre.

PORTO ALEGRE. PREFEITURA MUNICIPAL. Fundação de Assistência Social e Cidadania. Serviço de Apoio Socioeducativo em Meio Aberto. SASE. Abr. 2010. (Projeto técnico).

PORTO ALEGRE. PREFEITURA MUNICIPAL. Secretaria Municipal de Educação. Educação infantil-estrutura. Disponível em: <http://www2.portoalegre.rs.gov.br/ smed/default.php?p_secao=21>_Acesso em: 28 abr. 2012.

SILVA, M.L.; PAULO, F.; GRAZZIOLA, R. Educação popular e ensino superior: possíveis relações. Revista Educação Popular, Uberlândia, v. 9, p. 11-18, 2010. Disponível em: <http://www.revistadeeducacaopopular.proex.ufu.br>. Acesso em: 28 abr. 2012.

SPITZ, R. O primeiro ano de vida. 3. ed. São Paulo: Martins Fontes, 2004.

Recebido em 7 de julho de 2012.

Aprovado em 4 de abril de 2014. 